\title{
Study on the influencing factors of existing buildings green renovation in old residential areas
}

\author{
Yin Yanping ${ }^{1}, \mathrm{Gu} \mathrm{Hao}^{2}$, and Gu Xiangyang ${ }^{3}$ \\ ${ }^{1} X i$ 'an Railway Vocational and Technical Institute, Xi'an, China \\ ${ }^{2}$ The Third Engineering Branch of China Railway First Bureau, Baoji, China \\ ${ }^{3}$ Shaanxi Water Conservancy and Electric Power Survey and Design Institute, Xi'an, China
}

\begin{abstract}
Based on problems existing in the green transformation of existing buildings in old residential areas, this paper aims to find out the influencing factors that hinder the green transformation of existing buildings in old residential areas, so as to change the situation that the green transformation of existing buildings in old residential areas advances slowly. It uses the grounded theory based on "science and technology literature" and factor analysis method to determine the 16 key influencing factors and importance ranking, reliability test and validity test, and calculates the initial load square sum of squares, rotating load characteristic value, and the cumulative value indicators to extract six common factors and put forward some proposals for the results obtained from the analysis. Furthermore, it provides decision-making reference for the implementation of green transformation of existing buildings in old residential areas.
\end{abstract}

\section{Overview}

In response to the challenges of global climate change, shortage of resources and energy, and deterioration of the ecological environment, mankind is following the concept of carbon cycle, taking low-carbon as the guide, developing the circular economy, building low-carbon ecological cities, and popularizing low-carbon and green buildings. According to statistics, in 2017, China's building energy consumption was 947 million TCE, accounting for $21.11 \%$ of the national energy consumption. Among them, urban residential building area accounts for $37 \%$ and the energy consumption accounts for $38 \%$. It can be seen that the green transformation of existing buildings is an important breakthrough point to achieve sustainable development of the construction industry.

In recent years, the research on the impact of green renovation of existing buildings has been highly valued by the academic community. Foreign scholars explored the factors hindering its development from different perspectives. In terms of economy, Tuominen $\mathrm{P}$ and others concluded that the lack of strong willingness of all parties to renovate is due to the lack of capital ${ }^{1}$ appreciation and subsidy mechanism through an interview with stakeholders of existing building renovation ${ }^{[1]}$.In terms of technology, Caputo $\mathrm{P}$ and others investigated the most important obstacles to the green reconstruction of existing buildings and believed that the current reconstruction technology should be reformed to improve the reconstruction ability ${ }^{[2]}$.However, due to the late start of green renovation in China, there are few researches on the progress of green renovation of existing buildings. Yang and others analyzed the main factors affecting green renovation projects of industrial buildings through field research in 22 cities in China, which can be divided into three parts: economic factors, social factors and environmental factors ${ }^{[3]}$. Shen Ling and others believe that the huge renovation fund gap, long-term or uncertain payback period and other practical economic difficulties seriously hinder the promotion of green renovation of existing buildings ${ }^{[4]}$.

It can be seen from the above research that the domestic and foreign scholars have explored both the factors of restricting the development of green transformation of existing residential buildings from multiple perspectives, and most of them mainly use subjective analysis, lacking quantitative empirical data. There is a lack of comprehensive and systematic analysis and identification of key factors that hinder the green renovation of existing buildings in old communities. Therefore, this paper, based on the predecessors' researches, through the on-the-spot investigation Xi'an old community, adopting the method of questionnaire survey, systematically sorts out the influence factors that hinder the green transformation of existing buildings in old communities. Then factor analysis method is used to find out the key factors from above influencing factors, and relevant countermeasures and suggestions are put forward accordingly, which have guiding significance for promoting the progress of green reconstruction of the existing buildings in the old communities.

\footnotetext{
Corresponding author: ${ }^{2} 215382671 @ q q . c o m$

b810422839@qq.com
} 


\section{Model construction of the influencing factors that hinder the green transformation of existing buildings in the old community}

\subsection{Construction of the index system of influencing factors}

In order to explore the influencing factors that hinder the green renovation of old residential buildings and ensure the comprehensive and scientific indicators of the influencing factors, this paper will use the grounded theory method to construct the influencing factors index system of the green renovation of existing residential buildings. Based on the principle of "everything as data", this paper collects the existing recent scientific and technological literature, network data, industry experts' views and interview data in field research as the original data. The research mainly focused on manual coding, and it divided original data into 214 original records to code and carry out saturation test.

\subsection{Model construction of factor analysis}

\subsubsection{Reliability test}

Reliability test is used to test the consistency of the survey results, that is, the reliability of the survey results, and there will be no significant difference due to the difference of the survey objects and the survey time. Its calculation formula is shown in Equation (1):

$$
\alpha=\frac{k}{k-1}\left(1-\frac{\sum \sigma_{i}^{2}}{\sigma^{2}}\right)
$$

Where $\alpha$ - the reliability coefficient

$k$ - the number of questions in the questionnaire

$\sigma i 2$ _ variance of survey results in question i

$\sigma^{2}$ _ variance of all survey results

\subsubsection{Validity test}

Validity test is to test whether the selected indicators can truly feedback the measured concept. It is mainly considered through the partial correlation between the measured variables. The correlation between each factor and the result is checked through the test results, and determine whether it is suitable for factor analysis using principal component analysis. As shown in Equation (2):

$$
\begin{aligned}
& S_{T}{ }^{2}=S_{C}{ }^{2}+S_{D}{ }^{2}+S_{E}{ }^{2} \\
& \text { Val }=\frac{S_{C}{ }^{2}}{S_{T}{ }^{2}}
\end{aligned}
$$

Where $\mathrm{Val}$ - validity coefficient

$S_{T}^{2}$ - variance of real score

$S_{C}^{2}$ - test characteristic variance

$S_{D}^{2}$ - variances of other characteristics

$S_{E}^{2}$ - error variance

\subsubsection{Principal component analysis}

(1)Factor load and cumulative contribution rate

First of all, we need to standardize the different dimensions of each variable. The normalized matrix is obtained as follows:

$$
Z=\left[\begin{array}{cccc}
z_{11} & z_{12} & \cdots & z_{1 p} \\
z_{21} & z_{22} & \cdots & z_{2 p} \\
\vdots & \vdots & \vdots & \vdots \\
z_{n 1} & z_{n 2} & \cdots & z_{n p}
\end{array}\right]
$$

(2) Calculate the factor load, the correlation coefficient between variables and major factors, and get the correlation matrix R, also known as the factor load matrix, namely:

$$
R=\left[\begin{array}{cccc}
1 & & & \\
r_{21} & 1 & & \\
\vdots & \vdots & \ddots & \\
r_{n 1} & r_{n 2} & \cdots & 1
\end{array}\right]
$$

Where $r_{i j}$ is the correlation coefficient between the variables $\mathrm{Y}_{\mathrm{i}}$ and $\mathrm{Y}_{\mathrm{j}}$

$$
r_{i j}=\frac{\operatorname{cov}\left(Y_{i}, Y_{j}\right)}{\sqrt{D\left(Y_{i}\right.} \sqrt{D\left(Y_{j}\right)}}
$$

Where the $\operatorname{cov}\left(\mathrm{Y}_{\mathrm{i}}, \mathrm{Y}_{\mathrm{j}}\right)$ is the covariance of $\mathrm{Y}_{\mathrm{i}}$ and $\mathrm{Y}_{\mathrm{j}}$; $\mathrm{D}\left(\mathrm{Y}_{\mathrm{i}}\right)$ and $\mathrm{D}\left(\mathrm{Y}_{\mathrm{j}}\right)$ are the variances of $\mathrm{Y}_{\mathrm{i}}$ and $\mathrm{Y}_{\mathrm{j}}$ respectively.

2.2.4 Solve all characteristic roots $\lambda i$ of the sample correlation matrix $R_{i}$ and the corresponding normalized eigenvector $L_{i}$, Where $i=1,2 \ldots, n$, and use standardized eigenvectors to form an eigenvector matrix $L=\left(L_{1}, L_{2}, \ldots, L_{n}\right)$.

\subsubsection{Obtain the load matrix according to the characteristic roots and eigenvector:}

$$
A=\left(\sqrt{\lambda_{1}} L_{1}, \sqrt{\lambda_{2}} L_{2}, \cdots, \sqrt{\lambda_{n}} L_{n}\right)
$$

The first $\mathrm{k}$ column vector is taken as the factor loading matrix, and the cumulative contribution rate of the factor is required to be no less than $80 \%$, namely:

$$
\sum_{i=1}^{k} \lambda_{i} / \sum_{i=1}^{m} \lambda_{i} \geq 80 \%
$$

\section{Data collection and analysis}

After analyzing and organizing the network data of interview records and scientific and technological literature and deleting some weakly relevant factors and combining similar factors with grounded theory, 35 factors affecting the green renovation of existing buildings in old residential areas are obtained.

Questionnaire design uses 5 point Likert scale, the scale is composed of a set of statements, each statement has five answers: "very important", "important", "general", "not important" or "negligible", which are recorded as 5, 4, 3, 2 and 1 points respectively. 


\subsection{The ranking of the importance of influencing factors}

Relevant data were obtained by sorting out the questionnaire, and the mean value of 35 influencing factors was calculated. When the mean value of this factor is higher than the mean value of the population, it is considered that this factor is the main factor affecting the green reconstruction of the existing buildings in the old communities. After analysis and calculation, 16 factors whose mean value is higher than the overall mean value of the 35 influencing factors were selected as the key influencing factors affecting the green renovation of existing buildings in the old residential districts, and the importance of the 16 key influencing factors was ranked, as shown in Table 1. In order to obtain the common factors affecting the green renovation of the existing buildings in the old communities, the factor analysis of the 16 key influencing factors is needed.

Table 1 importance ranking of influencing factors

\begin{tabular}{|c|c|c|c|}
\hline $\begin{array}{c}\text { Serial } \\
\text { number }\end{array}$ & Name of factors & The average & $\begin{array}{l}\text { The } \\
\text { sorting }\end{array}$ \\
\hline A11 & $\begin{array}{c}\text { Large capital needs, financing } \\
\text { difficulties }\end{array}$ & 4.79 & 1 \\
\hline A24 & Social participation & 4.74 & 2 \\
\hline A4 & $\begin{array}{l}\text { The willingness of residents } \\
\text { for green renovation }\end{array}$ & 4.68 & 3 \\
\hline A12 & $\begin{array}{l}\text { The great government } \\
\text { financial pressure }\end{array}$ & 4.63 & 4 \\
\hline A14 & $\begin{array}{l}\text { The imperfect green } \\
\text { transformation policy }\end{array}$ & 4.60 & 5 \\
\hline $\mathrm{A} 2$ & Residents' interests & 4.54 & 6 \\
\hline A 35 & Green reform market defects & 4.49 & 7 \\
\hline A 31 & $\begin{array}{l}\text { The not sound green } \\
\text { transformation mechanism }\end{array}$ & 4.44 & 8 \\
\hline A16 & Policy effectiveness & 4.39 & 9 \\
\hline A9 & $\begin{array}{l}\text { The imperfect compensation } \\
\text { and subsidy mechanism }\end{array}$ & 4.33 & 10 \\
\hline A1 & $\begin{array}{c}\text { The intricate residents' } \\
\text { situation }\end{array}$ & 4.28 & 11 \\
\hline A22 & Inadequate preparation & 4.23 & 12 \\
\hline A6 & $\begin{array}{l}\text { Residents' cognition of green } \\
\text { reconstruction }\end{array}$ & 4.18 & 13 \\
\hline A29 & Green transformation scheme & 4.12 & 14 \\
\hline A26 & $\begin{array}{l}\text { The insufficient green } \\
\text { transformation technology }\end{array}$ & 4.09 & 15 \\
\hline A7 & $\begin{array}{c}\text { The imperfect incentive } \\
\text { system }\end{array}$ & 4.05 & 16 \\
\hline
\end{tabular}

\subsection{Factor analysis results}

\subsubsection{Reliability test.}

In this paper, the famous Cronbach's Alpha was used to test the reliability of the scale, and the data were analyzed and calculated. The following results are shown in Table 2.
Table 2 Reliability test

\begin{tabular}{ccc}
\hline \multicolumn{3}{c}{ Reliability statistics } \\
\hline Cronbach's & Cronbach's Alpha based \\
Alpha & on standardized items & Number of terms \\
.762 & .752 & 17 \\
\hline
\end{tabular}

It can be seen from the test results that the Cronbach's Alpha exceeds 0.7 , indicating a good consistency of the scale and an ideal test result. It also indicates that the analysis of this batch of data can well reflect the overall situation.

\subsubsection{Validity test.}

The results show that the KMO values of the 17 key influencing factors and Bartlett's test of Bartlett's sphericity meet the standard. As shown in Table 3, the $\mathrm{KMO}$ value is $0.816(>0.5)$, the approximate chi-square value is 189.209 , the degree of freedom is 120 , and the significance is 0.000 , which is very significant. It shows that this paper is suitable for the factor analysis of the factors affecting the green reconstruction of the existing buildings in the old communities.

Table $3 \mathrm{KMO}$ and Bartlett tests

\begin{tabular}{|c|c|c|}
\hline \multicolumn{2}{|c|}{ KMO sampling fitness measure } & .816 \\
\hline Bartlett's test for & $\begin{array}{c}\text { The approximate } \\
\text { chi-square }\end{array}$ & 189.209 \\
\hline sphericity & $\begin{array}{l}\text { Degrees of freedom } \\
\text { significance }\end{array}$ & $\begin{array}{l}120 \\
.000\end{array}$ \\
\hline
\end{tabular}

\subsubsection{Principal component analysis.}

Through relevant calculation, Table 4 is the interpretation table of total variance. According to the criterion for selecting common factors proposed by Kaiser that the initial eigenvalue is greater than 1 , six common factors whose initial eigenvalue is greater than 1 are extracted respectively according to the initial eigenvalue gravel diagram (Figure 1), the cumulative sum of the square of the rotation load of the six common factors reached $83.934 \%$, and most of the information of the original variables was retained. Therefore, six common factors were selected.

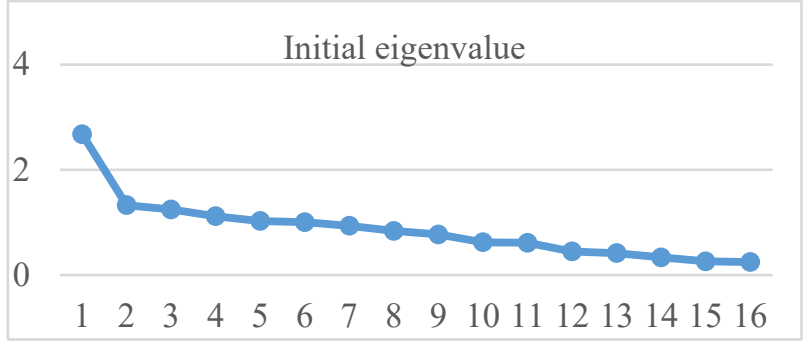

Fig. 1. Gravel diagram 
Table 4 Factor load table

\begin{tabular}{|c|c|c|c|c|c|c|c|c|c|}
\hline \multirow{3}{*}{$\begin{array}{c}\text { The } \\
\text { serial } \\
\text { number }\end{array}$} & \multicolumn{3}{|c|}{ Initial eigenvalue } & \multicolumn{3}{|c|}{$\begin{array}{l}\text { The sum of squares of the extraction } \\
\text { load }\end{array}$} & \multicolumn{3}{|c|}{$\begin{array}{c}\text { Sum of the squares of the rotating } \\
\text { loads }\end{array}$} \\
\hline & \multirow{2}{*}{$\begin{array}{c}\text { A } \\
\text { total } \\
\text { of }\end{array}$} & \multirow{2}{*}{$\begin{array}{c}\begin{array}{c}\text { The } \\
\text { variance }\end{array} \\
\begin{array}{c}\text { The } \\
\text { percentage }\end{array}\end{array}$} & \multirow{2}{*}{ Cumulative \% } & \multirow{2}{*}{$\begin{array}{c}\text { A } \\
\text { total } \\
\text { of }\end{array}$} & \multirow{2}{*}{$\begin{array}{c}\text { The } \\
\text { variance }\end{array}$} & \multirow{2}{*}{ Cumulative \% } & \multirow{2}{*}{$\begin{array}{c}\text { A } \\
\text { total } \\
\text { of }\end{array}$} & \multirow{2}{*}{$\begin{array}{c}\text { The } \\
\text { variance }\end{array}$} & \multirow{2}{*}{ Cumulative $\%$} \\
\hline & & & & & & & & & \\
\hline 1 & 2.675 & 26.751 & 26.751 & 2.675 & 26.751 & 26.751 & 1.873 & 18.732 & 18.732 \\
\hline 2 & 1.327 & 13.271 & 40.022 & 1.327 & 13.271 & 40.022 & 1.566 & 15.663 & 34.395 \\
\hline 3 & 1.246 & 12.456 & 52.478 & 1.246 & 12.456 & 52.478 & 1.461 & 14.612 & 49.007 \\
\hline 4 & 1.116 & 11.163 & 63.641 & 1.116 & 11.163 & 63.641 & 1.264 & 12.643 & 61.650 \\
\hline 5 & 1.026 & 10.26 & 73.901 & 1.026 & 10.26 & 73.901 & 1.148 & 11.450 & 73.100 \\
\hline 6 & 1.003 & 10.03 & 83.934 & 1.003 & 10.03 & 83.934 & 1.083 & 10.834 & 83.934 \\
\hline
\end{tabular}

\subsection{Result analysis}

By analyzing the component matrix after rotation in Table 5 , it can be seen that each factor only corresponds to a few indexes with larger factor loads, so indexes can be classified according to them.

Table 5 The matrix table after rotation

\begin{tabular}{ccccccc}
\hline & \multicolumn{5}{c}{ composition } \\
\cline { 2 - 7 } factors & 1 & 2 & 3 & 4 & 5 & 6 \\
\hline A11 & 0.804 & 0.147 & 0.129 & 0.179 & 0.052 & 0.133 \\
A24 & 0.727 & 0.824 & 0.289 & 0.264 & 0.201 & 0.098 \\
A4 & 0.54 & 0.308 & 0.828 & 0.228 & 0.142 & 0.114 \\
A12 & 0.877 & 0.413 & 0.063 & 0.302 & 0.179 & 0.224 \\
A14 & 0.506 & 0.122 & 0.224 & 0.823 & 0.263 & 0.177 \\
A2 & 0.301 & 0.823 & 0.813 & 0.113 & 0.145 & 0.231 \\
A35 & 0.405 & 0.813 & 0.467 & 0.138 & 0.207 & 0.333 \\
A31 & 0.078 & 0.293 & 0.064 & 0.824 & 0.828 & 0.115 \\
A16 & 0.135 & 0.402 & 0.304 & 0.805 & 0.203 & 0.102 \\
A9 & 0.566 & 0.17 & 0.118 & 0.306 & 0.137 & 0.809 \\
A1 & 0.24 & 0.147 & 0.808 & 0.208 & 0.343 & 0.128 \\
A22 & 0.128 & 0.025 & 0.226 & 0.147 & 0.819 & 0.064 \\
A6 & 0.148 & 0.245 & 0.795 & 0.195 & 0.643 & 0.219 \\
A29 & 0.103 & 0.169 & 0.274 & 0.184 & 0.812 & 0.458 \\
A26 & 0.113 & 0.332 & 0.403 & 0.523 & 0.802 & 0.666 \\
A7 & 0.347 & 0.117 & 0.143 & 0.359 & 0.112 & 0.784 \\
\hline
\end{tabular}

In the first factor, A11, A12 and A36 have larger loads and are directly related to capital, so F1 is named as the capital factor. In the ranking of importance of influencing factors in Table 1, it can be found that the financing difficulty factor ranks first, indicating that the problem is worthy of attention. In the second common factor, A24 and A35 have larger loads, reflecting the insufficient participation of social forces and the defects in the green transformation market, so F2 is named as the social input factor. In the third common factor, the four indicators A1, A2, A4 and A6 have larger loads, revealing the existing problems of residents, which greatly hinders the development process of green renovation of existing buildings in the old communities, so F4 is named as the resident behavior factor. In the fourth common factor, A14 and A16 have larger loads, which is manifested as the deficiency in government policies. F3 is named as the policy factor. In the fifth common factor, A22, A26, A29 and A31 have larger loads, which mainly reflects the problems of the green transformation of the existing buildings in the old communities in the early stage of the work, plan and technology, so F5 is named as the green transformation mechanism factor. In the sixth common factor, A7 and A9 have larger loads. The main reflection is the subsidy incentive system is not perfect. Therefore, F6 is named as the compensation incentive mechanism factor. As shown in the table below:

Table 6 Factor Naming Table

\begin{tabular}{|c|c|c|}
\hline $\begin{array}{l}\text { Common } \\
\text { factor }\end{array}$ & High load index & named \\
\hline Factor 1 & $\mathrm{~A} 11, \mathrm{~A} 12, \mathrm{~A} 36$ & Capital factor \\
\hline Factor 2 & A24, A35 & Social input factor \\
\hline Factor 3 & $\mathrm{~A} 1, \mathrm{~A} 2, \mathrm{~A} 4, \mathrm{~A} 6$ & $\begin{array}{l}\text { Resident behavior } \\
\text { factor }\end{array}$ \\
\hline Factor 4 & A14, A16 & Policy factors \\
\hline Factor 5 & $\mathrm{~A} 22, \mathrm{~A} 26, \mathrm{~A} 29, \mathrm{~A} 31$ & $\begin{array}{l}\text { Green transformation } \\
\text { mechanism factor }\end{array}$ \\
\hline Factor 6 & A7, A9 & $\begin{array}{l}\text { Compensate for } \\
\text { incentive factors }\end{array}$ \\
\hline
\end{tabular}

\section{4. conclusion}

\subsection{Conclusion 1}

According to the importance ranking of 35 influencing factors, from the perspective of single influencing factor, the major factors hindering the green renovation of existing buildings in old residential areas are the large capital demand, financing difficulties, social participation, residents' willingness to green reconstruction, great government financial pressure, imperfect green reconstruction policy, residents' interests, green reconstruction market defects, imperfect green reconstruction mechanism, policy effectiveness, imperfect compensation and subsidy mechanism, and the intricate residents' situation, insufficient preparation 
work, residents' cognition of green transformation, green transformation scheme, insufficient green transformation technology and imperfect incentive system.

\subsection{Conclusion 2}

The analysis shows that there is a strong correlation among the influencing factors. By calculating the initial characteristic value, the sum of the squares of the extracted load and the sum of the squares of the rotating load, the six common factors affecting the green reconstruction of the existing buildings in the old communities are extracted. They are: capital factor, social investment factor, policy factor, resident behavior factor, green transformation mechanism factor, subsidy and incentive mechanism factor.

\subsection{Conclusion 3}

On the whole, at the government level, the main factors hindering the green renovation of existing buildings in old residential areas are lack of funds, insufficient policies on green renovation of existing buildings in old residential areas, and imperfect incentive compensation mechanism. On the social level, the main factors are the lack of social participation and the defects of green reform market. At the level of residents, the key factors are residents' willingness of green reconstruction and residents' interests.

\section{Countermeasures and Suggestions}

\subsection{Innovate investment and financing mechanisms and establish diversified investment and financing channels}

Capital is a necessary condition for the green renovation of existing buildings in old residential areas. A special fund for the green renovation should be established to encourage financial institutions and local governments to actively explore and increase financial support for the green renovation in a sustainable way.

\subsection{Strengthen the participation of social forces and improve the market mechanism for green transformation}

From the perspective of the whole of the project with a long-term view, the green renovation is in strict accordance with the national green building standards. It cooperates with the government to introduce more advanced green technology and professional and technical personnel. We should view the transform as a kind of opportunity and market of value creation and innovation. In this way, the process of green transformation of existing buildings in the old communities will be promoted.

\subsection{Do a good job in coordination and communication to enhance residents' willingness for green reconstruction}

Local governments should strengthen the publicity of the advantages of green reconstruction of existing buildings in old residential areas, build a platform for resource and information exchange and interaction, establish a networked trust relationship, and let more residents have a deep understanding, so as to improve residents' willingness.

\section{References}

1. Tuominen P, Klobut K, Tolman A, etc. Energy savings potential in buildings and overcoming market barriers in member states of the European Union[J]. Energy and Buildings, 2012, 51: 48-55.

2. Caputo P, Pasetti G. Overcoming the inertia of building energy retrofit at municipal level: The Italian challenge[J]. Sustainable Cities and Society, 2015, 15: 120-134.

3. Y Zhang, H Li. Analysis on the influencing factors of green renovation of old industrial buildings based on SEM-Taking the development stage as an example[J]. Journal of Xi'an University of Architecture and Technology (Natural Science Edition), 2015,47(05):689-693.

4. L Shen, W Zhao, Y Mou. Innovation of PPP Model for green renovation of existing residential building from the perspective of community participation [J]. Journal of Civil Engineering and Management, 2019, 36(01):8-15+23. 